\title{
From tubular sublimate nephropathy via urinary concentrating mechanism to glomerular disease-Wilhelm Kriz's contribution to modern nephrology
}

\author{
On the occasion of a symposium honoring Wilhelm Kriz on his 80th birthday
}

\author{
Sebastian Bachmann ${ }^{1,2}$ (D)
}

Received: 24 May 2017 /Revised: 1 June 2017 / Accepted: 1 June 2017 / Published online: 24 June 2017

(C) Springer-Verlag GmbH Germany 2017

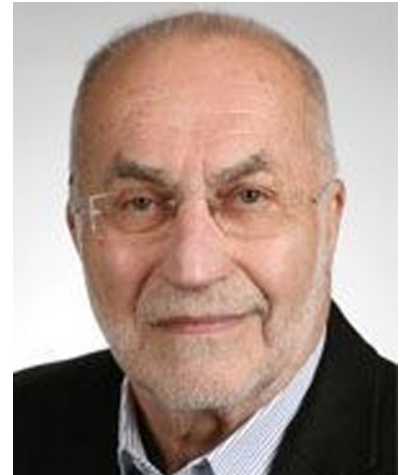

Prof. Dr. med. Wilhelm Kriz

On the occasion of the 80th birthday of Prof. Dr. med. Wilhelm Kriz, Professor emeritus of Anatomy of the University of Heidelberg, Germany, a symposium entitled "The kidney in health and disease - concepts and perspectives from renal architecture" was held in Berlin on May 19 and 20. This special issue of Pflügers Archiv-European Journal of Physiology entitled "Functional anatomy of the kidney in health and disease" is a compilation of expert review articles that were provided from colleagues participating at the

This article is part of the special issue on Functional Anatomy of the Kidney in Health and Disease in Pflügers Archiv - European Journal of Physiology

Sebastian Bachmann

sbachm@ charite.de

1 Department of Anatomy, Charité Universitätsmedizin, 10115 Berlin, Germany

2 Institut für Vegetative Anatomie, Charité - Universitätsmedizin Berlin, Campus Charité-Mitte, Philippstr. 12, 10115 Berlin, Germany symposium in honor of Wilhelm Kriz. The title of the special issue accounts for the major impact of anatomically oriented research Wilhelm Kriz has accomplished.

\section{On his way to kidney research}

Wilhelm Kriz is from Strobnitz, today Horni Stropnice, near Budweis/Ceske Budejovice in the Czech Republic, the site of famous actions of "the good soldier Svejk." Kriz was born on November 9, 1936, as the son of a dentist. With the turmoil of World War II having come to an end, his family had to leave home and moved West so that Kriz went to school in Hessen in the town of Lauterbach where he graduated with the abitur in 1957. Right after school, he went to nearby Gießen University to study medicine. He finished early with his state medical examination and was awarded his medical degree in 1963. He decided to stay on with the anatomists, a clear proof of his dedication to structure-based science. Consequently, he worked for another 2 years in Gießen, and then formally accepted a position as an anatomy instructor and scientific assistant at the University of Münster, where he became an associate professor in 1971 in the department of Heinz Rollhäuser. At the young age of 38 , he next received a call to his final position as a full professor and chairman in the Department of Anatomy, University of Heidelberg, which then received the proud surname "and Cell Biology," following a previous concept from Giessen University. After construction of the modern science campus of Heidelberg University, Kriz and his cochairmen, Dariush Fahimi and Wolf-Georg Forssmann, created a fruitful science atmosphere in three independent anatomy departments (Lehrstühle). There was brisk scientific exchange among these colleagues, and a long-standing, very successful 
anatomy teaching approach was developed. This was with essential input from Wilhelm Kriz, who was so undisputedly strong and knowledgeable among his colleagues in microscopic and gross anatomy teaching that his lectures were often followed by other faculty members who were keen to hereby save energy, get inspiration, and prepare for their own turn.

His research activities were a love affair with the kidney from early on. In PubMed, his track record starts with a first publication of his thesis on sublimate poisoning in rat kidney published in Zeitschrift für Zellforschung in 1962 [37] that stimulated his interest in diuretics. Ultimately proving to be a thoughtful character all his life, seeking solutions to existing or novel questions, he became fascinated by questions of functional anatomy of the entire kidney, a rich source given the multiplicity of cell types and zonal architectural topography housed in this fascinating organ.

His research interests over time can be categorized into three major sectors, including (1) the structural organization of the mammalian kidney; (2) structure-function correlations in the glomerulus, thin limbs of Henle's loop and distal tubule, juxtaglomerular apparatus, and interstitium, all related to glomerular filtration, epithelial performance, the urine concentrating mechanism, and adaptive processes; and (3) renal pathology with a focus on glomerular diseases, chronic renal failure, renal interstitial disease, and diabetic nephropathy. Many ground-breaking new concepts have emerged from these studies, and comprehensive conclusions from the different areas of his research have always led him to produce brilliant, textbook-ready review articles on the structure of the entire kidney or parts of it, containing not only the world's best pictures on nearly all renal structures but also schematic designs which were unprecedented and visionary in precision, logic, and didactic clarity. As a result, today's kidney literature uses his conceptual drawings as the first choice, making him the world's leader in the demonstration of the kidney's structures. It is due to this fact that Kriz is now widely referred towith a twinkle in the eye-as the "Michelangelo of the kidney." For students of medicine, physiology, and biology, his drawings have entered the textbooks in all countries in original or modified form, and his legendary, continuously updated chapter "Structural and functional organization of the kidney" together with Brigitte Kaissling in Seldin and Giebisch's magnum opus The Kidney is a reference for all morphology-related questions occurring to interested researchers worldwide. A substantial number of other book chapters by Kriz have appeared over time, like those in Windhager's and Heptinstall's comprehensive works, and the pioneering opus on the structural landmarks of the renal concentrating mechanism, written together with Rex Jamison, who provided the functional part. A very fruitful extension of Kriz's book articles is a textbook article for standard medical education in Benninghoff's textbook on human anatomy, edited by Detlev Drenckhahn (Urban and Schwarzenberg 2005), which contains a description of the kidney's functional anatomy for German medical students unparalleled in its clarity.

\section{Kidney vasculature and lymphatic system}

The wide range of his scientific work will be categorized briefly, but in some detail. Kriz put much effort into the structural analysis of the vascular and lymphatic system of the kidney in his initial work. Before the functional background of multiple exchange pathways constituting the function of the renal concentrating mechanism, the arrangement of arterial and venous vessel types in the particular kidney zones was pioneering work, allowing understanding of the complex relation between tubular segments, interstitium, and blood vessels in the renal medulla $[6,18,39,41,44,45,68,85]$. Analyses across several species revealed the structural correlates of wet vs. arid habitats with animals displaying short vs. long papillae and further parenchymal specificities. By then, this became an issue of major interest for colleagues such as Lise Bankir and Bodil Schmidt-Nielsen as well as the group of Arvid Maunsbach, who exchanged their ideas actively and in part published together. A long-standing collaboration with Lise Bankir from Paris had its origin here. The interests in the medullary microcirculation of Kevin Lemley, a Humboldt fellow in Kriz's laboratory, trained at Stanford University, met with Kriz's analyses and provided the basis for long-standing collaboration as well.

\section{Architecture of the kidney}

Further work on more general aspects of the structure of the kidney was the basis of various comprehensive book chapters (v.s.) $[26,28,36,54]$. Crucially, important work on the general structure of the mammalian kidney was done together with Hermann Koepsell, who later became chair of the department of anatomy in Würzburg, and long-standing collaborator and congenial morphologist Brigitte Kaissling, who left Heidelberg in 1982 for stays in Yale, Basel, and her final destination of Zurich. Kaissling and Kriz's essential and ground-breaking analysis of the structure of the rabbit kidney contributed essentially to the fine structural definition of renal cell types of the three major compartments of the mammalian kidney, the vasculature, the nephron, and the interstitium [28].

\section{The renal medulla and urinary concentrating mechanism}

The still enigmatic interplay between the medullary vasculature and the segments of Henle's loop, specifically with respect to Hargitay and Kuhn's idea of the countercurrent 
multiplication principle enunciated in 1951 , then stimulated him to study the detailed morphology of the epithelia of the loop of Henle [3, 8, 9, 13, 32, 59, 61, 88]. A long-standing collaboration with Jürgen Schnermann began in 1971 and produced two major papers on the topography and heterogeneous width of the loop portions $[32,61]$. Beginning with the physiologists Schnermann and Christian de Rouffignac, external support for functional interpretations of the structural data became a major principle in Kriz's concepts of functional morphology. The introduction of freeze fracture techniques accelerated the understanding of thin limb epithelial cell membrane structure, although some of the details visualized by this technique remained unexplained in those days $[59,88]$. Comparing the extremes of urinary concentration ability across species, a clear picture emerged on how epithelial subtypes (chiefly of the thin limbs) are histotopographically arranged, and the multitude of cellular junction modes along with the principle of cellular interdigitation came to the fore. This would be followed by similar principles throughout much of Kriz's later work. Probing the medulla for local ion concentrations in those days was another major step in understanding the concentration gradients of the renal medulla [33, 60]. Measuring functional oxygen deficiency together with Joachim Schurek, another long-term collaborator with a physiological and clinical background, was another step towards understanding major questions in medullary function [91]. Achievements on thin limb and vasa recta structures along with these functional insights thus provided the basis for future considerations, particularly regarding the countercurrent exchange processes between vasa recta and the loop segments $[24,40,66,69]$. The emerging structural concepts on the functions accomplished by the distinct constituents of the renal medulla thus led Kriz and Rex Jamison to express their ideas in a comprehensive and, at that time, very innovative oeuvre termed "urinary concentrating mechanism" [24], outlining in great detail for the first time how the mammalian kidney forms urine of widely varying solute concentrations (Fig. 1).

I am sure this work has also substantially stimulated ensuing studies modeling renal solute handling and the concentrating mechanism with a mathematical background, e.g., by Alan Weinstein, Harold Layton, Anita Layton, and others, who calculated transport and diffusion quantities to and from the respective compartments under specific diuresis and solute homeostasis conditions. The paper entitled "Cycles and separations" by Lemley and Kriz, which appeared in 1987 [66], reviews the acquired knowledge in a nearly philosophical but functionally oriented manner, highlighting that the histotopographical organization of the renal medulla would permit predictions regarding details of the function of the concentrating mechanism. In fact, this paper, along with the former monograph [24], was an important precursor not only to a conceptual understanding of renal medullary function but also

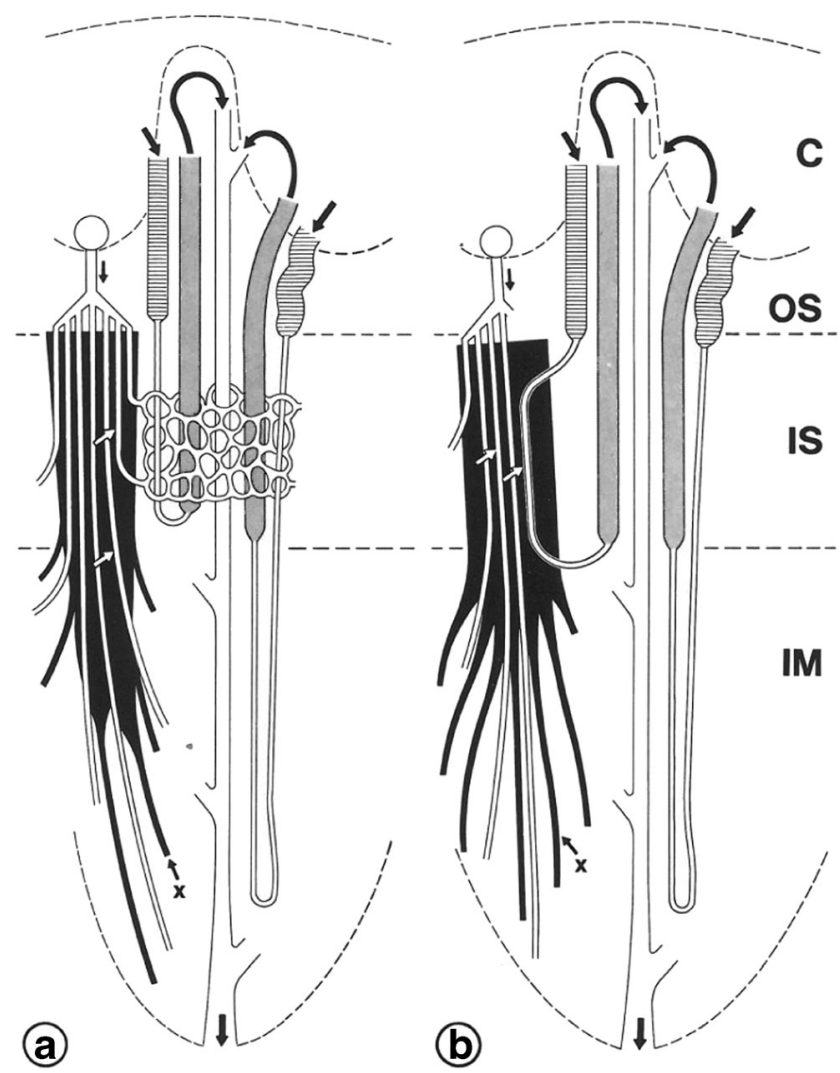

Fig. 1 Simple type (a) and complex type (b) of medullary organization of vasa recta, capillaries, segments of the loop of Henle, and the collecting ducts. Arrows indicate recycling routes, with a referring to an exchange of solutes between ascending and descending vasa recta, and $\mathbf{b}$ between ascending vasa recta and descending thin limbs of short-looped nephrons. From [24] with permission

to the attractive eight-step model of urine concentration outlined by Kriz for German medical students in Benninghoff's anatomy textbook (v.s.). In the same context, a meticulous and beautiful description of the renal interstitium elucidated not only its medullary but also its cortical landmarks and topographical characteristics in the light of the massive local exchange processes between the adjacent compartments [65].

\section{The renal interstitium and parameters of renal failure}

Early on, Kriz showed an interest in the anatomical changes and general causes involved in the pathology of acute renal failure, with his doctoral thesis exploring a link between sublimate poisoning and renal failure; later collaboration with Schurek, June Mason, and others illuminated the role of local oxygen supply as well as local cell swelling in interstitial narrowing with consequent vascular congestion and tubular obstruction [37, 70, 91]. By that time, it was recognized from the work of Kriz and others that the outer stripe of the outer 
medulla plays a predominant role in classical states of acute renal failure and their potential modes of resolution.

\section{Structure of the renal tubule}

Based on Kaissling and Kriz's seminal analysis of the structure of the rabbit kidney [28], and in parallel to studies on the medullary organization, Kriz started to work on the structure of the renal tubule together with Brigitte Kaissling, Sebastian Bachmann, and others; rapid progress was achieved along with parallel work from the laboratories of Arvid Maunsbach and Craig Tisher in Aarhus and Florida, respectively, as well as a few other, more functionally oriented pioneers [2, 4, 27, 29]. Here, Kriz, together with Kaissling, Bachmann, Will Minuth, and Werner Franke from Deutsches Krebsforschungszentrum in Heidelberg (DKFZ), elucidated the multiplicity of structures of various tubular segments and entered the field of immunohistochemical identification of specific proteins and their segmental distribution, likely inspired by the beautiful work of Dennis Brown at Harvard. Cell type heterogeneity of the renal tubule gained much attention. The proximal tubule became defined by its sub-segmentation into P1-P3 segments; medullary and cortical portions of the distal tubule, the connecting tubule, and the cortical and medullary portions of the collecting duct were defined by means of ultrastructural criteria. The phenomenon of cellular interdigitation as a means of membrane surface amplification was recognized, and the heterogeneity of tight junctional morphology was carefully considered in those years, with respect to discussions on transcellular vs. paracellular transport of water and ions. Importantly, these studies enabled Lise Bankir and Kriz to publish their famous categorization of kidney structures ("A standard nomenclature for structures of the kidney") in reaction to a globally prevailing uncertainty as to how to assign internationally applicable terms in the kidney; the proposed terms became globally accepted to an amazing extent, so that today, only minor confusion recurrently occurs, such as how to refer to "ascending thin limbs" and other medullary segments with the respective abbreviations proposed in [43].

\section{Functional adaptations of the renal tubule}

Based on the hitherto defined order of the segments of the renal tubule, Kriz, together with Bankir, Kaissling, and later Marlies Elger, entered a new field of functional morphology, defining adaptive changes of the renal tubule. Major questions in those days were focused on the altered performances of individual tubule segments under conditions like renal mass reduction, vasopressin-induced changes and related alterations in salt and water handling, increases in glomerular filtration rate (GFR) related with high protein intake (a concept chiefly propagated by Barry Brenner), and changes under chronic loop diuretic treatment, the latter chiefly to understand the clinically observed "Lasix escape phenomenon" $[5$, $10-12,14,25,42,98]$. Research on these fascinating issues was later extended and perfected at the cell biological level by his disciple, Brigitte Kaissling, during her ensuing career.

\section{Glomerular mesangium and juxtaglomerular apparatus}

He would not have been himself if Kriz had left untouched the clinically most important structure of the nephron, the glomerulus, and its regulatory neighborhood, the juxtaglomerular apparatus - stimulated by lively local discussions with his physiology/pharmacology colleagues, Michael Steinhausen, Rainer Nobiling, Hartmut Kirchheim, Roland Taugner, and Eberhard Hackenthal and Detlev Ganten and, as a sabbatical visitor, Bernd Sterzel from Yale with his particular interest in pathology. Further developments in this field were done in part in intense collaboration with the anatomist Tatsuo Sakai from Tokyo, another fellow from the Humboldt foundation and longterm faithful and creative disciple of Kriz [15, 16, 19, 71, 75, 86, $90,102]$. Stimulated by the particular interest of nephrologists in the mesangium, its physiological functions, and its assumed central role in glomerular disease at that time, Kriz focused his research interest on the general mesangial tissue structure, mostly of the intraglomerular mesangium, but also, with respect to juxtaglomerular function, of the then still enigmatic "Polkissen" (lacis cells of Goormaghtigh) or extraglomerular mesangium. On the one hand, the relation of mechanical forces transmitted between mesangium and glomerular basement membrane was clarified, and on the other, the Polkissen was meticulously described with respect to its intimate neighborhood [74, $89,94,96]$, although better clarification of its role still had to wait a number of years until Jürgen Schnermann was able to identify a major signaling pathway involving adenosine and adenosine receptors. Since at that time, the structure and function of the renin-containing granular cells of the afferent arteriole were subject to lively discussions [72], Kriz described a periarterial space thought to be relevant for intrarenal renin distribution upon cellular release [38]. The discovery of nitric oxide synthase in the cells of the macula densa together with his thesis student, Peter Mundel, as well as Bachmann and others caused much excitement about potential juxtaglomerular regulatory functions, but disappointingly had little consequences for our understanding of physiology or clinical medicine [74] in contrast to Raymond Harris's later finding of co-expressed cyclooxygenase-2.

\section{Podocytes}

Kriz's interest in the epithelial side of the glomerulus, i.e., the podocytes, began early as well, when the link between 
mesangial function, the basement membrane, and podocyte integrity came into question [86]. One basic consideration suggesting the need for intensified research on this cell type was the question of whether podocyte structure could adapt to functional needs so that GFR could effectively be regulated by mechanical force transmission between mesangium, basement membrane, and podocytes, or by local adjustments of podocytes themselves with the help of their cytoskeleton; another was that Kriz became interested in the structure of the slit diaphragm and related foot process arrangements before not only a physiological but also a disease-related background. It was clear at that time that podocytes were involved in the pathogenesis of glomerular disease, but evidence was available only at a descriptive level. Nevertheless, pursuing intensified research on podocytes rather than on the mesangium was a major, if not the crucial, step in Kriz's later work, since his initial studies on podocyte biology today are considered seminal, inasmuch as studying podocyte biology later became the centerpiece of contemporary nephrology research over the past two decades. In parallel, Kriz's early concepts on functional morphology were endorsed by the enlightening insights from human genetics when Karl Tryggvason, Marie-Claire Gubler, Corinne Antignac, and others showed the first molecular-based approaches to function and disease attributable to components of the glomerular filter around the turn of the millennium. A broad array of experimental techniques from many disciplines was subsequently employed. Today, podocyte research has most obviously taken center stage in nephrology, with currently 1130 review articles on podocytes available on the net, and even the term podocytopathy is now sporadically in use in clinical cases and glomerular research when dealing with the diseased podocyte [1].

Concentrating on podocytes, Kriz worked together with a number of extremely engaged thesis students and colleagues, among them Peter Mundel, then later Jochen Reiser, Matthias Kretzler, Nicole Endlich, Karlhans Endlich, and Hermann Pavenstädt [1, 17, 31, 76-79, 83, 84]. As before, he continually received essential support from his technical staff group which included Hiltraud Hosser, Brunhilde Hähnel, Inge Hartmann, and the institution's artist-in-residence, Rolf Nonnenmacher, who furnished not only technical supply but also important long-term archive functions and specific contributions on histological analyses and graphic modeling which is reflected by multiple co-authorships. Kriz's crucial input in podocyte research was "classically" a functionalmorphological one, and with progress it became evident that a clear, structure-related concept of podocyte biology was urgently needed. It became most helpful to understand the many identified proteins of the glomerular filter in their physiological meaning and pathological role when changes such as foot process effacement and resulting glomerulosclerosis, or loss of podocytes into the urine, were considered. Research on podocytes in Kriz's laboratory started with the work of Peter Mundel, who had been fighting hard for several years during his thesis to identify his "characteristic $44 \mathrm{kD}$ protein" associated with the actin cytoskeleton [1], which later was termed synaptopodin for its co-expression in podocyte foot processes and telencephalic dendrites [77], laying the cornerstone for subsequent attempts to combine kidney and brain research at a broader scale. With the tool of cultured podocytes made available in the laboratory by Mundel, functional studies in podocytes were facilitated [78, 79]. On the way to a molecular understanding of the functioning of the filtration barrier, initial insights came from cytochemical and cell biological studies at that time, demonstrating adherens-like differentiation of the slit diaphragm and F-actin-related mechanosensitive responses within podocytes [17, 84] (Fig. 2).

\section{Glomerular pathology}

Focusing on the podocytes under pathological conditions now stimulated Kriz to create a long series of remarkable, structure-based models, all presented with very clearly designed schematics in parallel to the original high-resolution state-of-the-art microscopy-based preparations, which had a major impact on colleagues reflecting about glomerular functions and diseases. Studying degenerative glomerular disease, Kriz has collaborated over the years with a number of national and international experts in the field of nephrology, pathology, genetics, and cell biology [20-23, 35, 48-52, 62, 67, 80, 81, 95, 99]; among them, Michio Nagata from Tokyo was another visitor to the laboratory with interest in pediatric nephrology, having a long-standing fruitful collaboration with Kriz on structure-based mechanisms of the podocyte's response to stress with the consequence of foot process effacement [62, 80, 81]. Initially with Sterzel [95], then with Lemley, Elger, Robert Koesters, the Heidelberg pathologists Rüdiger Waldherr and Hermann-Josef Gröne, Abraham Provoost from Rotterdam, Sigrid Hoffmann and Norbert Gretz from Mannheim, thesis students Matthias Kretzler, Soren Uiker, Sami Hakroush, and others, meticulous analyses on changes, observed chiefly under experimental focal segmental glomerular sclerosis (FSGS), were performed that ended up in concepts such as the misdirected filtrate model which caused much controversy or discussion but also opened new perspectives illustrated by Kriz on the pathogenesis of renal tubulointerstitial disease [50] (Fig. 3).

\section{Glomerular degeneration-inflammatory}

The distinct categories of glomerulopathies were another long-standing interest of Kriz's group, and much original work was further invested to identify common mechanisms 


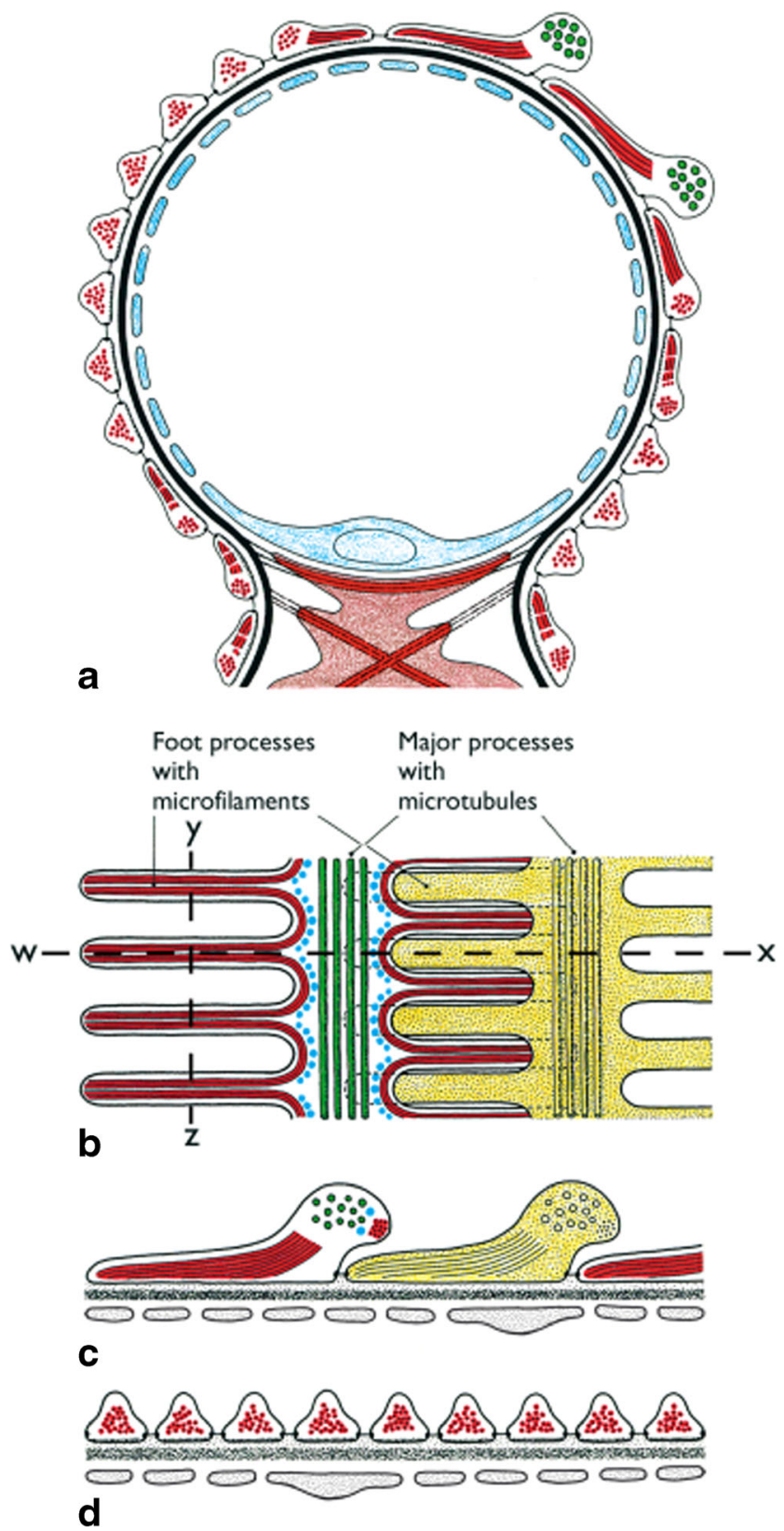

Fig. 2 In this drawing, Kriz shows the cytoskeleton of podocyte primary and foot processes. A cross section through a glomerular capillary loop shows foot processes containing actin-based contractile filaments ( red; a). Primary processes contain bundles of microtubules (green; b). A flat section shows both processes (b). Perpendicular arrangement of filaments and microtubules (c). High resolution of filaments (d). From [83] with permission (color figure online)

of glomerular degeneration. Inflammatory glomerular degeneration was analyzed in a number of studies together with yet another long-term guest and collaborator from Japan, Isao Shirato, along with his postdoctoral fellow Marcus Möller, Jürgen Floege from Aachen, Michel LeHir from Zurich, Roger Wiggins from Ann Arbor, Larry Holzman from Philadelphia, and the Bachmann group [47, 63, 73, 82, 92, 93, 97]. Chiefly, the basic structure-related idea was

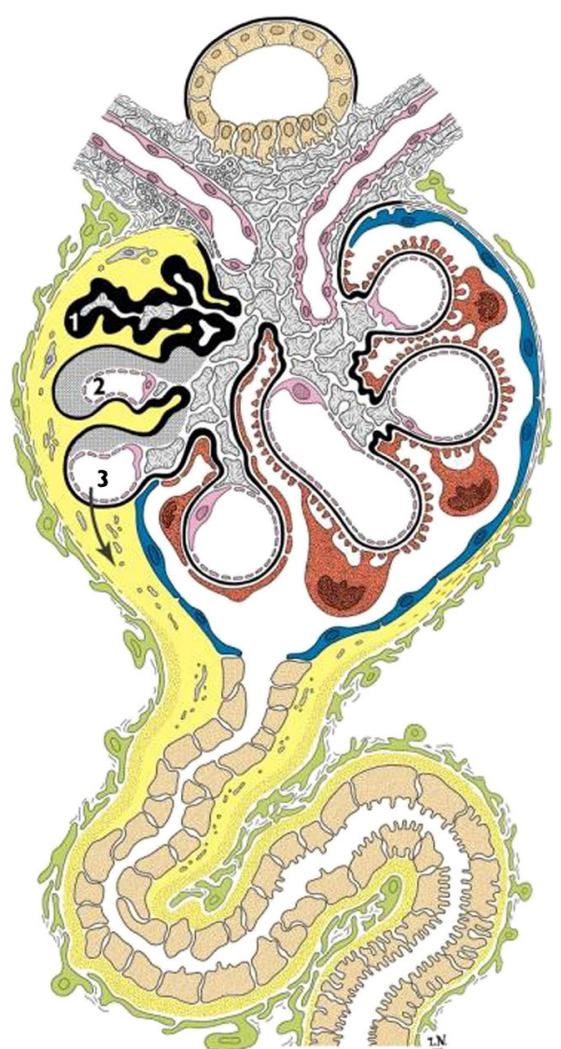

Fig. 3 In this schematic, Kriz illustrates his idea of misdirected filtrate formation in the course of glomerular degeneration. The glomerular basement membrane (black) surrounds collapsed (1) and hyalinizing capillary loops $(2,3)$ in the sclerotic sector. A new pathway has been opened after disappearance of the parietal epithelium, which allows the misdirected filtrate to enter a paraglomerular space, from where it enters a subepithelial space in the proximal tubule. This process is thought to induce tubular obstruction. From [50] with permission

developed that podocytes, when challenged in glomerular disease, develop general, stereotyped structural changes which include hypertrophy, cell body attenuation, pseudocyst formation, foot process effacement, intracellular accumulation of debris, and detachment from the glomerular basement membrane [93]. Studying recovery from damage, remodeling of the foot processes was considered to follow a programmed course in which effacement was considered an adaptive change that can be transitory in nature. Studying mesangioproliferative glomerulonephritis in anti-Thy-1 nephritic rats, a closer look on the role of Bowman's capsule came into play and a meticulously developed concept for the chain of events including the deleterious extracapillary changes, adhesion of the podocytes to Bowman's capsule, and the consequent route of misdirected glomerular filtrate obstructing and disconnecting the tubule, eventually leading to degeneration of the entire nephron, was a novelty with significant impact on the pathologist's view of inflammatory degenerative changes of the glomerulus [47]. It was further stressed then that no evidence could be found that injured nephrons were harmful to neighboring healthy nephrons, a 
view which was debated substantially at that time in the light of prevailing concepts of tubulointerstital fibrotic changes. Providing better evidence for these concepts, Möller, Holzman, and colleagues generated an impressive array of transgenic constructs to characterize together with Kriz the initial changes and interactions between podocytes and parietal cells of the capsule during crescent formation [73].

\section{Glomerular degeneration-collapsing}

Studying collapsing glomerulosclerosis and HIV-associated nephropathy as examples with little or no chance for reversibility, common pathomechanisms were identified. Here, podocyte dysregulation was shown to be the centerpiece and primary indicator on the way to glomerular collapse, with disappearance of crucial markers for podocyte lineage, along with cell proliferation [7]. Changes were clearly distinct from those occurring in minimal change disease and membranous GN and helped to identify this specific form of FSGS, and stages of degeneration were characterized.

\section{Glomerular degeneration-general}

Experiments in the isolated perfused rat kidney, initially begun with Schurek, opened the way to understanding the role of podocytes in counteracting distending forces in the glomerular capillaries [46, 64, 87]. In recent work, Kriz and Lemley have resumed studies to newly define influences of mechanical forces including shear stress on the detachment of podocytes and reconciling that the major way podocytes seem to exit the tuft is as viable cells. A new role for the slit diaphragm to mechanically stabilizing the effects of shear stress forces on opposing podocyte foot processes is a major component of Kriz's present understanding [55-57]. Kriz's most recent work has been dedicated to the role of mesangial matrix expansion in diabetic nephropathy in the context of typical basement membrane thickening, which precedes damage and loss of podocytes [58]. Reversibility of the changes is explained thereby. Retrospectively, success and scientific advancement in the sector of podocyte research has been impressively mirrored by 11 international podocyte conferences held so far, with the last one organized by Suheir Assadi, Karl Skorecki, and Tobias Huber in Haifa and Jerusalem, Israel (April 2016) [1]; these high-ranking meetings have substantially profited from the ideas and incentive by Kriz and his group over time.

\section{Renal tubulointerstitium}

Kriz's late work on the tubulointerstitium received much attention as well $[30,34,53]$. Together with Gröne's group,
Kaissling, and LeHir, the rising dogma of the central pathogenetic role of epithelial-to-mesenchymal transition (EMT) in conjunction with enhanced release of TGF- $\beta 1$ in the context of peritubular interstitial fibrosis induced by transformed tubular epithelial cells was questioned. A transgenic mouse model with tubular overexpression of TGF- $\beta 1$ was used to provide evidence against the dogma and helped to demonstrate that interstitial fibrosis develops from fibroblasts transforming into matrix-overexpressing myofibroblasts, whereas tubular epithelial cells underwent dedifferentiation and subsequent autophagy, but always remained within limits of the tubular basement membrane [34]. This data and subsequent work [30,53] helped to clarify the issue substantially so that today, a clear credo from Kriz and his collaborators is that fibrosis itself actually fulfills protective tasks and that under circumstances of progression, glomerular damage is necessarily involved to encroach on the tubule, leading to nephron loss and fibrotic replacement, eventually causing a vicious cycle of progressive decay. These studies have had a major impact on the gradual retreat from the EMT concept in contemporary discussions of tubulointerstitial fibrosis.

\section{Plastination for anatomy}

An interesting side project of Wilhelm Kriz is worth mentioning. One of his assistants, Gunter von Hagens, originally coming from pathology, decided to say farewell to renal anatomy, after collaborating with Kriz on what he called "tubulating." In the mid-1980s, von Hagens gathered a solid number of medical students to address gross anatomy in his own way, that is, by revitalizing techniques of past centuries with contemporary polymer techniques in order conserve the human body, including all its organs, in life-like quality. The potential of this technique was soon recognized by Kriz who published first data on the potential of plastination as early as in 1987 together with von Hagens and his colleague, Klaus Tiedemann [100].

After an enormous effort, applying hectoliters of dangerous and inflammable solvents and polymer compounds, the first "plastified" bodies as well as life-like-looking organs were made available to academic teaching centers and soon received worldwide attention which peaked with the "Body Worlds/Körperwelten," the most visited traveling exposition ever shown with so far over 40 million visitors worldwide. Kriz's role in enabling this development was a central one, since he had endorsed von Hagen's activities from early on. Despite enduring controversial discussions about human body plastination, Kriz had been supportive of von Hagens' earlyever unconventional-activities wherever improvement of teaching of gross anatomy, in its purely academic form or aimed at the general population, was an issue. Kriz was also particularly fascinated by the new methodology to 
demonstrate the anatomy of the brain, consisting of plastinated slices which at that time reflected the structural detail in the second and third dimensions most accurately [101], until the widespread use of computer tomography replaced these techniques.

\section{Academic landmarks}

In his long scientific career in Heidelberg, Wilhelm Kriz has been acting as the Dean of the "Fakultät für Naturwissenschaftliche Medizin" in his Alma mater (197677), he has been member of the board of examiners responsible for the general examinations in medicine in Germany for 22 years, a member of the governing board of the University of Heidelberg for 14 years, a member of two referee boards for the Heisenberg Society and the Deutsche Forschungsgemeinschaft, and head of the board of examiners for dental students at the University of Heidelberg. Most remarkably, after becoming emeritus professor in 2005, Kriz has served in the Department of Anatomy in Heidelberg, and from 2006 in Mannheim as an acting chairman until 2012, with full teaching duties and undiminished research activities. Even today, in his 80th year, he participates in teaching anatomy and continues to actively publish his scientific work in well-respected nephrology journals. He served as a speaker in an impressive number of research consortia including the Research Group on "Funktionelle und strukturelle Adaptation der Niere," supported by "Deutsche Forschungsgemeinschaft" (1986-1993), the Research Group "Grundlagen, Genese und Folgen der chronischen Niereninsuffizienz," supported by Land BadenWürttemberg (1986-1993), the Graduiertenkolleg "Experimentelle Nieren- und Kreislaufforschung," supported by "Deutsche Forschungsgemeinschaft" (1990-2000), the Research Group "Mechanismen der Zellproliferation und Zelldiffenzierung in der Niere - Orthologie und Pathologie," supported by Land Baden-Württemberg (1995-1997), the Research Group "Mechanismen der Progression des chronischen Nierenversagens," supported by "Deutsche Forschungsgemeinschaft" (2001-2006), and the "Post-Doc Collegium" of the Medical Faculty of Heidelberg (2000 2005). Among the honors he received were the Jakob Henle Medal 1990 (sic!) from the University of Göttingen, the Bernd Tersteegen-Award 1998 from the German Dialysis Society, the Franz Volhard Medal 2007 from the Deutsche Gesellschaft für Nephrologie, and the Homer Smith Award 2010 from the American Society of Nephrology.

Truly, like Homer Smith's scientific heritage, Wilhelm Kriz's opus already now deserves utmost respect regarding his sustainable impact in scientific education aimed at the understanding of the kidney's multiple functions by means of a structure-guided approach. Theoreticians and clinicianscientists have both profited substantially from his work.
Together with his colleagues, collaborators, and the numerous disciples and graduates, I express the best wishes for his 80th birthday, continued activities in science and teaching, and a healthy life among his family at home.

Acknowledgements I hereby wish to thank Dr. Kevin Lemley MD, Pediatric Nephrology, Los Angeles, and Martin Thomsen, Anatomie Berlin, for correcting the manuscript.

\section{Compliance with ethical standards}

Disclosures None

\section{References}

1. Assady S, Wanner N, Skorecki KL, Huber TB (2017) New insights into podocyte biology in glomerular health and disease. J Am Soc Nephrol

2. Bachmann S, Koeppen-Hagemann I, Kriz W (1985) Ultrastructural localization of Tamm-Horsfall glycoprotein (THP) in rat kidney as revealed by protein A-gold immunocytochemistry. Histochemistry 83:531-538

3. Bachmann S, Kriz W (1982) Histotopography and ultrastructure of the thin limbs of the loop of Henle in the hamster. Cell Tissue Res 225:111-127

4. Bachmann S, Kriz W, Kuhn C, Franke WW (1983) Differentiation of cell types in the mammalian kidney by immunofluorescence microscopy using antibodies to intermediate filament proteins and desmoplakins. Histochemistry 77:365-394

5. Bankir L, Fischer C, Fischer S, Jukkala K, Specht HC, Kriz W (1988) Adaptation of the rat kidney to altered water intake and urine concentration. Pflugers Arch 412:42-53

6. Bankir L, Kaissling B, de Rouffignac C, Kriz W (1979) The vascular organization of the kidney of Psammomys obesus. Anat Embryol (Berl) 155:149-160

7. Barisoni L, Kriz W, Mundel P, D'Agati V (1999) The dysregulated podocyte phenotype: a novel concept in the pathogenesis of collapsing idiopathic focal segmental glomerulosclerosis and HIVassociated nephropathy. J Am Soc Nephrol 10:51-61

8. Barrett JM, Kriz W, Kaissling B, de Rouffignac C (1978) The ultrastructure of the nephrons of the desert rodent (Psammomys obesus) kidney. I. Thin limb of Henle of short-looped nephrons. Am J Anat 151:487-497

9. Barrett JM, Kriz W, Kaissling B, de Rouffignac C (1978) The ultrastructure of the nephrons of the desert rodent (Psammomys obesus) kidney. II. Thin limbs of Henle of long-looped nephrons. Am J Anat 151:499-514

10. Bouby N, Bankir L, Trinh-Trang-Tan MM, Minuth WW, Kriz W (1985) Selective ADH-induced hypertrophy of the medullary thick ascending limb in Brattleboro rats. Kidney Int 28:456-466

11. Bouby N, Trinh-Trang-Tan MM, Kriz W, Bankir L (1987) Possible role of the thick ascending limb and of the urine concentrating mechanism in the protein-induced increase in GFR and kidney mass. Kidney Int Suppl 22:S57-S61

12. Bouby N, Trinh-Trang-Tan MM, Laouari D, Kleinknecht C, Grunfeld JP, Kriz W, Bankir L (1988) Role of the urinary concentrating process in the renal effects of high protein intake. Kidney Int 34:4-12

13. Dieterich HJ, Barrett JM, Kriz W, Bulhoff JP (1975) The ultrastructure of the thin loop limbs of the mouse kidney. Anat Embryol (Berl) 147:1-18 
14. Elger M, Bankir L, Kriz W (1992) Morphometric analysis of kidney hypertrophy in rats after chronic potassium depletion. Am J Phys 262:F656-F667

15. Elger M, Sakai T, Kriz W (1998) The vascular pole of the renal glomerulus of rat. Adv Anat Embryol Cell Biol 139:1-98

16. Elger M, Sakai T, Winkler D, Kriz W (1991) Structure of the outflow segment of the efferent arteriole in rat superficial glomeruli. Contrib Nephrol 95:22-33

17. Endlich N, Kress KR, Reiser J, Uttenweiler D, Kriz W, Mundel P, Endlich K (2001) Podocytes respond to mechanical stress in vitro. J Am Soc Nephrol 12:413-422

18. Frank M, Kriz W (1988) The luminal aspect of intrarenal arteries and veins in the rat as revealed by scanning electron microscopy. Anat Embryol (Berl) 177:371-376

19. Frank M, Kriz W (1982) Scanning electron microscopy studies of the vascular pole of the rat glomerulus. Anat Rec 204:149-152

20. Gassler N, Elger M, Inoue D, Kriz W, Amling M (1998) Oligonephronia, not exuberant apoptosis, accounts for the development of glomerulosclerosis in the bcl-2 knockout mouse. Nephrol Dial Transplant 13:2509-2518

21. Gassler N, Elger M, Kranzlin B, Kriz W, Gretz N, Hahnel B, Hosser H, Hartmann I (2001) Podocyte injury underlies the progression of focal segmental glomerulosclerosis in the fa/fa Zucker rat. Kidney Int 60:106-116

22. Hakroush S, Moeller MJ, Theilig F, Kaissling B, Sijmonsma TP, Jugold M, Akeson AL, Traykova-Brauch M, Hosser H, Hahnel B, Grone HJ, Koesters R, Kriz W (2009) Effects of increased renal tubular vascular endothelial growth factor (VEGF) on fibrosis, cyst formation, and glomerular disease. Am J Pathol 175:18831895

23. Hoffmann S, Podlich D, Hahnel B, Kriz W, Gretz N (2004) Angiotensin II type 1 receptor overexpression in podocytes induces glomerulosclerosis in transgenic rats. J Am Soc Nephrol 15:1475-1487

24. Jamison RL, Kriz W (1982) Urinary concentrating mechanism, First Edition edn. Oxford University Press, Oxford

25. Kaissling B, Bachmann S, Kriz W (1985) Structural adaptation of the distal convoluted tubule to prolonged furosemide treatment. Am J Phys 248:F374-F381

26. Kaissling B, de Rouffignac C, Barrett JM, Kriz W (1975) The structural organization of the kidney of the desert rodent Psammomys obesus. Anat Embryol (Berl) 148:121-143

27. Kaissling B, Kriz W (1982) Axial heterogeneity of the 'distal tubule'. Contrib Nephrol 33:29-47

28. Kaissling B, Kriz W (1979) Structural analysis of the rabbit kidney. Adv Anat Embryol Cell Biol 56:1-123

29. Kaissling B, Kriz W (1982) Variability of intercellular spaces between macula densa cells: a transmission electron microscopic study in rabbits and rats. Kidney Int Suppl 12:S9-17

30. Kaissling B, Lehir M, Kriz W (2013) Renal epithelial injury and fibrosis. Biochim Biophys Acta 1832:931-939

31. Kobayashi N, Reiser J, Kriz W, Kuriyama R, Mundel P (1998) Nonuniform microtubular polarity established by CHO1/MKLP1 motor protein is necessary for process formation of podocytes. $\mathrm{J}$ Cell Biol 143:1961-1970

32. Koepsell H, Kriz W, Schnermann J (1972) Pattern of luminal diameter changes along the descending and ascending thin limbs of the loop of Henle in the inner medullary zone of the rat kidney. Z Anat Entwicklungsgesch 138:321-328

33. Koepsell H, Nicholson WA, Kriz W, Hohling HJ (1974) Measurements of exponential gradients of sodium and chlorine in the rat kidney medulla using the electron microprobe. Pflugers Arch 350:167-184

34. Koesters R, Kaissling B, Lehir M, Picard N, Theilig F, Gebhardt R, Glick AB, Hahnel B, Hosser H, Grone HJ, Kriz W (2010) Tubular overexpression of transforming growth factor-betal induces autophagy and fibrosis but not mesenchymal transition of renal epithelial cells. Am J Pathol 177:632-643

35. Kretzler M, Koeppen-Hagemann I, Kriz W (1994) Podocyte damage is a critical step in the development of glomerulosclerosis in the uninephrectomised-desoxycorticosterone hypertensive rat. Virchows Arch 425:181-193

36. Kriz W (1967) The architectonic and functional structure of the rat kidney. Z Zellforsch Mikrosk Anat 82:495-535

37. Kriz W (1962) Histophysiological studies on the rat kidney in sublimate poisoning. With a contribution on the genesis of anuria. Z Zellforsch Mikrosk Anat 57:914-952

38. Kriz W (1987) A periarterial pathway for intrarenal distribution of renin. Kidney Int Suppl 20:S51-S56

39. Kriz W (1982) Structural organization of renal medullary circulation. Nephron 31:290-295

40. Kriz W (1983) Structural organization of the renal medullary counterflow system. Fed Proc 42:2379-2385

41. Kriz W, Bachmann S (1985) Pre- and postglomerular arterioles of the kidney. J Cardiovasc Pharmacol 7(Suppl 3):S24-S30

42. Kriz W, Bankir L (1982) ADH-induced changes in the epithelium of the thick ascending limb in Brattleboro rats with hereditary hypothalamic diabetes insipidus. Ann N Y Acad Sci 394:424-434

43. Kriz W, Bankir L (1988) A standard nomenclature for structures of the kidney. The renal Commission of the International Union of Physiological Sciences (IUPS). Kidney Int 33:1-7

44. Kriz W, Barrett JM, Peter S (1976) The renal vasculature: anatomical-functional aspects. Int Rev Physiol 11:1-21

45. Kriz W, Dieterich HJ (1970) The lymphatic system of the kidney in some mammals. Light and electron microscopic investigations. Z Anat Entwicklungsgesch 131:111-147

46. Kriz W, Hackenthal E, Nobiling R, Sakai T, Elger M, Hahnel B (1994) A role for podocytes to counteract capillary wall distension. Kidney Int 45:369-376

47. Kriz W, Hahnel B, Hosser H, Ostendorf T, Gaertner S, Kranzlin B, Gretz N, Shimizu F, Floege J (2003) Pathways to recovery and loss of nephrons in anti-Thy-1 nephritis. J Am Soc Nephrol 14: 1904-1926

48. Kriz W, Hahnel B, Hosser H, Rosener S, Waldherr R (2014) Structural analysis of how podocytes detach from the glomerular basement membrane under hypertrophic stress. Front Endocrinol (Lausanne) 5:207

49. Kriz W, Hahnel B, Rosener S, Elger M (1995) Long-term treatment of rats with FGF-2 results in focal segmental glomerulosclerosis. Kidney Int 48:1435-1450

50. Kriz W, Hartmann I, Hosser H, Hahnel B, Kranzlin B, Provoost A, Gretz N (2001) Tracer studies in the rat demonstrate misdirected filtration and peritubular filtrate spreading in nephrons with segmental glomerulosclerosis. J Am Soc Nephrol 12:496-506

51. Kriz W, Hosser H, Hahnel B, Simons JL, Provoost AP (1998) Development of vascular pole-associated glomerulosclerosis in the fawn-hooded rat. J Am Soc Nephrol 9:381-396

52. Kriz W, Hosser H, and Provoost A (1995) Podocyte damage is a major step in the development of glomerulosclerosis in the fawnhooded rat. Kindey Int 48

53. Kriz W, Kaissling B, Le Hir M (2011) Epithelial-mesenchymal transition (EMT) in kidney fibrosis: fact or fantasy? J Clin Invest 121:468-474

54. Kriz W, Koepsell H (1974) The structural organization of the mouse kidney. Z Anat Entwicklungsgesch 144:137-163

55. Kriz W, Lemley KV (2017) Mechanical challenges to the glomerular filtration barrier: adaptations and pathway to sclerosis. Pediatr Nephrol 32:405-417

56. Kriz W, Lemley KV (2017) Potential relevance of shear stress for slit diaphragm and podocyte function. Kidney Int 
57. Kriz W, Lemley KV (2015) A potential role for mechanical forces in the detachment of podocytes and the progression of CKD. J Am Soc Nephrol 26:258-269

58. Kriz W, Lowen J, Federico G, van den Born J, Grone E, Grone HJ (2017) Accumulation of worn-out GBM material substantially contributes to mesangial matrix expansion in diabetic nephropathy. Am J Physiol Renal Physiol. doi:10.1152/ajprenal.00020. 2017

59. Kriz W, Schiller A, Taugner R (1981) Freeze-fracture studies on the thin limbs of Henle's loop in Psammomys obesus. Am J Anat 162:23-33

60. Kriz W, Schnermann J, Höhling HJ, von Rosenstiel AP, Hall TA (1971) Electron probe microanalysis of electrolytes in kidney cells. Karger 162-171

61. Kriz W, Schnermann J, Koepsell H (1972) The position of short and long loops of Henle in the rat kidney. Z Anat Entwicklungsgesch 138:301-319

62. Kriz W, Shirato I, Nagata M, LeHir M, Lemley KV (2013) The podocyte's response to stress: the enigma of foot process effacement. Am J Physiol Renal Physiol 304:F333-F347

63. Le Hir M, Keller C, Eschmann V, Hahnel B, Hosser H, Kriz W (2001) Podocyte bridges between the tuft and Bowman's capsule: an early event in experimental crescentic glomerulonephritis. J Am Soc Nephrol 12:2060-2071

64. Lemley KV, Elger M, Koeppen-Hagemann I, Kretzler M, Nagata M, Sakai T, Uiker S, Kriz W (1992) The glomerular mesangium: capillary support function and its failure under experimental conditions. Clin Investig 70:843-856

65. Lemley KV, Kriz W (1991) Anatomy of the renal interstitium. Kidney Int 39:370-381

66. Lemley KV, Kriz W (1987) Cycles and separations: the histotopography of the urinary concentrating process. Kidney Int 31:538-548

67. Lemley KV, Kriz W (1991) Glomerular injury in analbuminemic rats after subtotal nephrectomy. Nephron 59:104-109

68. Lemley KV, Zimmerhackl B, Jamison RL, Kriz W (1986) The shape of renal vasa recta capillaries and its effect on calculation of single capillary blood flow. Microvasc Res 32:1-20

69. Lever AF, Kriz W (1966) Countercurrent exchange between the vasa recta and the loop of Henle. Lancet 1:1057-1060

70. Mason J, Joeris B, Welsch J, Kriz W (1989) Vascular congestion in ischemic renal failure: the role of cell swelling. Miner Electrolyte Metab 15:114-124

71. Mbassa G, Elger M, Kriz W (1988) The ultrastructural organization of the basement membrane of Bowman's capsule in the rat renal corpuscle. Cell Tissue Res 253:151-163

72. Minuth WW, Nobiling R, Hackenthal E, Taugner R, Kriz W (1986) Long-term culture of renin containing tissue. Histochemistry $84: 131-138$

73. Moeller MJ, Soofi A, Hartmann I, Le Hir M, Wiggins R, Kriz W, Holzman LB (2004) Podocytes populate cellular crescents in a murine model of inflammatory glomerulonephritis. J Am Soc Nephrol 15:61-67

74. Mundel P, Bachmann S, Bader M, Fischer A, Kummer W, Mayer B, Kriz W (1992) Expression of nitric oxide synthase in kidney macula densa cells. Kidney Int 42:1017-1019

75. Mundel P, Elger M, Sakai T, Kriz W (1988) Microfibrils are a major component of the mesangial matrix in the glomerulus of the rat kidney. Cell Tissue Res 254:183-187

76. Mundel P, Gilbert P, Kriz W (1991) Podocytes in glomerulus of rat kidney express a characteristic $44 \mathrm{KD}$ protein. J Histochem Cytochem 39:1047-1056

77. Mundel P, Heid HW, Mundel TM, Kruger M, Reiser J, Kriz W (1997) Synaptopodin: an actin-associated protein in telencephalic dendrites and renal podocytes. J Cell Biol 139:193-204
78. Mundel P, Reiser J, Kriz W (1997) Induction of differentiation in cultured rat and human podocytes. J Am Soc Nephrol 8:697-705

79. Mundel P, Reiser J, Zuniga Mejia Borja A, Pavenstadt H, Davidson GR, Kriz W, Zeller R (1997) Rearrangements of the cytoskeleton and cell contacts induce process formation during differentiation of conditionally immortalized mouse podocyte cell lines. Exp Cell Res 236:248-258

80. Nagata M, Kriz W (1992) Glomerular damage after uninephrectomy in young rats. II. Mechanical stress on podocytes as a pathway to sclerosis. Kidney Int 42:148-160

81. Nagata M, Scharer K, Kriz W (1992) Glomerular damage after uninephrectomy in young rats. I. Hypertrophy and distortion of capillary architecture. Kidney Int 42:136-147

82. Neumann I, Birck R, Newman M, Schnulle P, Kriz W, Nemoto K, Yard B, Waldherr R, Van Der Woude FJ (2003) SCG/Kinjoh mice: a model of ANCA-associated crescentic glomerulonephritis with immune deposits. Kidney Int 64:140-148

83. Pavenstadt H, Kriz W, Kretzler M (2003) Cell biology of the glomerular podocyte. Physiol Rev 83:253-307

84. Reiser J, Kriz W, Kretzler M, Mundel P (2000) The glomerular slit diaphragm is a modified adherens junction. J Am Soc Nephrol 11: $1-8$

85. Rollhaeuser H, Kriz W, Heinke W (1964) The vascular system of the rat kidney. Z Zellforsch Mikrosk Anat 64:381-403

86. Sakai T, Kriz W (1987) The structural relationship between mesangial cells and basement membrane of the renal glomerulus. Anat Embryol (Berl) 176:373-386

87. Sakai T, Lemley KV, Hackenthal E, Nagata M, Nobiling R, Kriz W (1992) Changes in glomerular structure following acute mesangial failure in the isolated perfused kidney. Kidney Int 41: 533-541

88. Schiller A, Taugner R, Kriz W (1980) The thin limbs of Henle's loop in the rabbit. A freeze fracture study. Cell Tissue Res 207: 249-265

89. Schnabel E, Kriz W (1984) Morphometric studies of the extraglomerular mesangial cell field in volume expanded and volume depleted rats. Anat Embryol (Berl) 170:217-222

90. Schnabel E, Kriz W, Steinhausen M (1988) Outflow segment of the efferent arteriole of the rat glomerulus investigated by in vivo and electron microscopy. Ren Physiol 10:318-326

91. Schurek HJ, Kriz W (1985) Morphologic and functional evidence for oxygen deficiency in the isolated perfused rat kidney. Lab Investig 53:145-155

92. Shirato I, Hosser H, Kimura K, Sakai T, Tomino Y, Kriz W (1996) The development of focal segmental glomerulosclerosis in masugi nephritis is based on progressive podocyte damage. Virchows Arch 429:255-273

93. Shirato I, Sakai T, Kimura K, Tomino Y, Kriz W (1996) Cytoskeletal changes in podocytes associated with foot process effacement in Masugi nephritis. Am J Pathol 148:1283-1296

94. Spanidis A, Wunsch H, Kaissling B, Kriz W (1982) Threedimensional shape of a Goormaghtigh cell and its contact with a granular cell in the rabbit kidney. Anat Embryol (Berl) 165:239 252

95. Sterzel RB, Luft FC, Gao Y, Schnermann J, Briggs JP, Ganten D, Waldherr R, Schnabel E, Kriz W (1988) Renal disease and the development of hypertension in salt-sensitive Dahl rats. Kidney Int 33:1119-1129

96. Taugner R, Schiller A, Kaissling B, Kriz W (1978) Gap junctional coupling between the JGA and the glomerular tuft. Cell Tissue Res 186:279-285

97. Theilig F, Kriz W, Jerichow T, Schrade P, Hahnel B, Willnow T, Le Hir M, Bachmann S (2007) Abrogation of protein uptake through megalin-deficient proximal tubules does not safeguard against tubulointerstitial injury. J Am Soc Nephrol 18:1824-1834 
98. Trinh-Trang-Tan MM, Bouby N, Kriz W, Bankir L (1987) Functional adaptation of thick ascending limb and internephron heterogeneity to urine concentration. Kidney Int 31:549-555

99. Uiker S, Kriz W (1995) Structural analysis of the formation of glomerular microaneurysms in the Habu venom model. Virchows Arch 426:281-293
100. von Hagens G, Tiedemann K, Kriz W (1987) The current potential of plastination. Anat Embryol (Berl) 175:411-421

101. von Hagens G, Whalley A, Maschke R, and Kriz W (1990) Schnittanatomie des menschlichen Gehirns

102. Winkler D, Elger M, Sakai T, Kriz W (1991) Branching and confluence pattern of glomerular arterioles in the rat. Kidney Int Suppl 32:S2-S8 